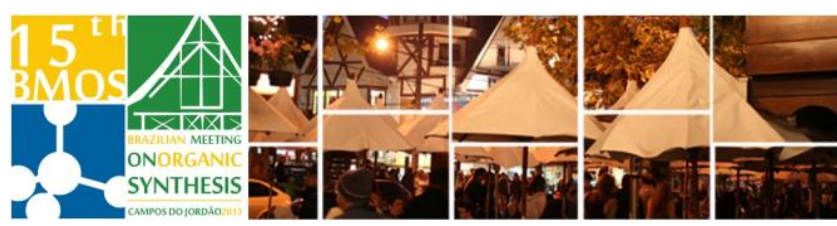

\title{
Synthesis and evaluation against Trypanosoma cruzi of naphthoquinone-containing triazoles
}

\author{
Emilay B. T. Diogo, ${ }^{a}$ Gleiston G. Dias, ${ }^{a}$ Wagner O. Valença, ${ }^{b}$ Celso A. Camara, ${ }^{b}$ \\ Mauro G. da Silva, ${ }^{\mathrm{b}}$ Ronaldo N. de Oliveira, ${ }^{\mathrm{b}}$ Rubem F. S. Menna-Barreto, ${ }^{\mathrm{c}}$ Solange L. \\ de Castro ${ }^{c}$ and Eufrânio N. da Silva Júnior ${ }^{\mathrm{a}^{*}}$ \\ ${ }^{a}$ Instituto de Ciências Exatas, Departamento de Química, UFMG, MG, Brazil; ${ }^{b}$ Departamento de Ciências \\ Moleculares, UFRPE, PE, Brazil; 'Laboratório de Biologia Celular, IOC, FIOCRUZ, RJ, Brazil.
}

*eufranio@ufmg.br

Keywords: Lapachol, $\beta$-Lapachone, Quinone, Chagas disease, Click chemistry.

\section{INTRODUCTION}

Chagas disease (CD), caused by the protozoan Trypanosoma cruzi, affects approximately eight million individuals in Latin America. ${ }^{1}$

$C D$ is characterized by a short acute phase defined by patent parasitemia and a long and progressive chronic phase. Up to $40 \%-50 \%$ of chronically infected patients develop progressive cardiomyopathy and/or motility disturbances of the esophagus and colon. The available chemotherapy for $C D$ is not satisfactory depending on two heterocyclic agents, nifurtimox and benznidazole. ${ }^{2}$

Naphthoquinones are considered privileged structures in medicinal chemistry due to their structural properties and biological activities. Recently, we have described the synthesis, trypanocidal and leishmanicidal activity of lapachone-based 1,2,3-triazoles. ${ }^{3}$ In this context, herein we describe the synthesis and evaluation against $T$. cruzi of 1,2,3-triazole substituted paraand ortho- naphthoquinones.

\section{RESULTS AND DISCUSSION}

Compounds 1-10, $N$-phthalimidoalkyl-azides, and 11-12 were initially synthesized and used in a click chemistry reaction with substituted 2-(prop-2yn-1-ylamine)-naphthoquinone to obtain the respective triazole compounds in high yields (Scheme 1).

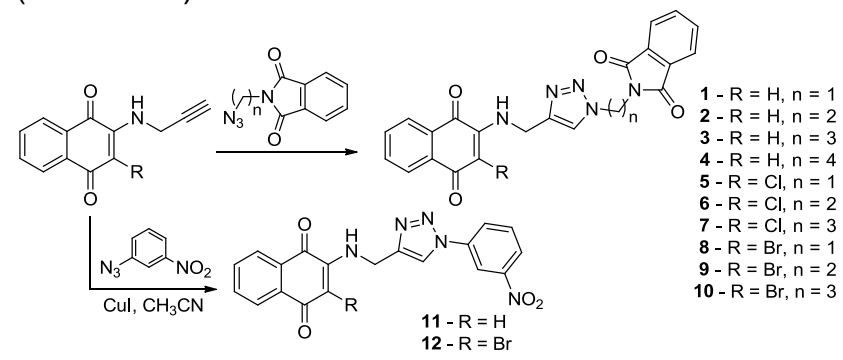

Scheme 1. Obtention of para-quinones 1-12.

Ortho-quinones were synthesized from the intermediate azide 13 previously described. ${ }^{3}$ To prepare the novel derivatives 14-16, naphthoquinones substituted by a terminal alkyne were obtained and used in the click chemistry reaction (Scheme 2). Nor- $\beta$-lapachone derivatives 14-16 were isolated in moderate yields.

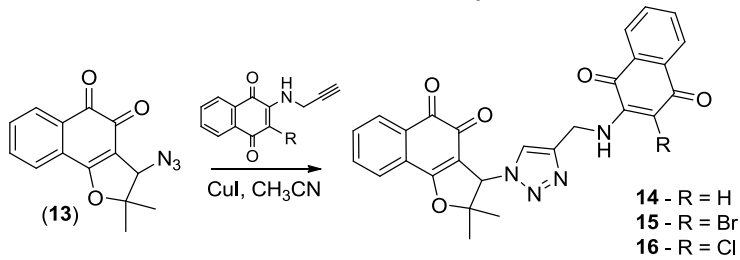

Scheme 2. Obtention of ortho-quinones 14-15.

The substances 1-12 were not active against $T$. cruzi with $\mathrm{IC}_{50} / 24 \mathrm{~h}>4000 \mu \mathrm{M}$. Compounds 14-15 was planned in order to obtain ortho-quinonecoupled to para-quinoidal structure (Scheme 2). Our strategy was effective and the substances 14-16 presented $\mathrm{IC}_{50} / 24 \mathrm{~h}$ values $=80.8,6.8$ and $8.2 \mu \mathrm{M}$, respectively. When compared with benznidazole, the standard drug used against $T$. cruzi, compounds 15 and 16 were fifteen and twelve times more active than anti- $T$. cruzi drug benznidazole.

\section{CONCLUSION}

We synthesized and evaluated fifteen substances and three potent trypanocidal compounds were identified, more active than the anti- $T$. cruzi drug benznidazole, the standard anti- $T$. cruzi drug. Compound $\mathbf{1 5}$ was fifteen times more active than benznidazole and this substance is a promising candidate for further investigations.

\section{ACKNOWLEDGEMENTS}

This research was supported by grants from the CNPq, CAPES, FAPEMIG, FAPEAL, FACEPEPRONEM, Fiocruz and UFMG.

\section{REFERENCES}

${ }^{1}$ Rassi Júnior, A.; Rassi, A.; Rezende, J. M. Infect. Dis. Clin. North Am. 2012, 26, 275

${ }^{2}$ Soeiro, M. N. C.; de Castro, S. L. Open Med. Chem. J. 2011, 5, 21.

${ }^{3}$ Guimarães, T. T.; Pinto, M. C. F. R.; Lanza, J. S.; Melo, M. N.; do MonteNeto, R. L.; de Melo, I. M. M.; Diogo, E. B. T.; Ferreira, V. F.; Camara, C.

A.; Valença, W. O.; de Oliveira, R. N.; Frézard, F.; da Silva Júnior, E. N. Eur. J. Med. Chem. 2013, 63, 523. 